\title{
Marine Fish Toxins in Thailand: Report of 6 Suspected Ciguatera Cases
}

\author{
Abhinbhen Saraya ${ }^{1 *}$, Chirapol Sintunawa2, Supaporn Wacharapluesadee ${ }^{1}$, \\ Kusuma Swangpun ${ }^{3}$, Supaluck Dumrongchua ${ }^{3}$, Henry Wilde', Thiravat Hemachudha1 \\ ${ }^{1}$ Neuroscience Centre for Research and Development, Division of Neurology, Department of Medicine, Faculty \\ of Medicine, Chulalongkorn University and King Chulalongkorn Memorial Hospital, Bangkok, Thailand \\ ${ }^{2}$ Faculty of Environment and Resource Studies, Mahidol University, Bangkok, Thailand \\ ${ }^{3}$ Phuket Provincial Public Health Office, Ministry of Public Health, Bangkok, Thailand \\ Email: abhinbhen@gmail.com
}

Received 18 March 2014; revised 15 April 2014; accepted 5 May 2014

Copyright (C) 2014 by authors and Scientific Research Publishing Inc.

This work is licensed under the Creative Commons Attribution International License (CC BY). http://creativecommons.org/licenses/by/4.0/

(c) (i) Open Access

\begin{abstract}
Food poisoning or gastroenteritis is a common diagnosis for individuals who have nausea, vomiting and diarrhea after ingestion of fish. When also manifesting neurological symptoms, these are blamed on puffer fish poisoning, but ciguatera fish poisoning (CFP) can also manifest only with gastroenteritis, without neurological complications and remain undiagnosed. We report patients who fulfilled criteria of CFP suffering from severe GI disturbances, neurological manifestations, compromised cardiovascular status and autonomic dysfunction. All recovered within 1 - 3 days with supportive treatment. There were two small outbreaks: one in Bangkok in 2007 (2 patients) and another (2009) in Phuket (4 patients). All patients consumed the same unidentified fish portion and had severe GI symptoms. One had acute ventilatory failure requiring intubation whereas the remaining had neurological disturbances consisting of paresthesia, severe vertigo and ataxia. Absence of reflex tachycardia was noted in all patients who had severe volume depletion and shock. The most severe patient could be extubated within 24 hours and was discharged in 48 hours. All of the remaining recovered completely within 48 hours. Severe abdominal pain, nausea and vomiting and autonomic dysfunction in the form of bradycardia in the presence of hypotension were seen. Dramatic recovery within 48 hours occurred in all cases. None of the fish considered to have been responsible was available for testing. Physicians should be aware of CFP intoxication in the differential diagnosis of gastroenteritis-like syndromes after eating seafood.
\end{abstract}

\section{Keywords}

Component, Ciguatera, Marine Toxins, Ciguatoxin, Food-Borne Diseases

\footnotetext{
*Corresponding author.
} 


\section{Introduction}

The most common marine toxin worldwide is ciguatera. Many types of reef-fish are vulnerable to accumulate ciguatera toxin (CTX). This is particularly true for barracuda, grouper, sea bass, snapper, and amberjack [1] [2]. The endemic areas of ciguatera are in latitudes between 35 north and south. The origin of the toxin is from dinoflagellate algae, principally the coral reef species Gambierdiscus toxicus [2]. Reef disturbances and global warming increase the risk of ciguatera by increasing benthic substrate for dinoflagellate growth [3]. Destruction of coral reefs aid increased growth of algae and their dinoflagellates [4]. This may also be influenced by the degree of sunlight exposure in the presence of silicates and oxides from adjacent land soils; and with algal detritus resulting in the development of peculiar algal turfs Turbinaria, Jania and Amphiroa species. Such growth patterns presumably underlie the spatial and temporal variability of ciguatera outbreaks.

CTX is a lipophillic polyether that can open voltage sensitive $\mathrm{Na}^{+}$channels at the neuromuscular junction. It causes hyper-excitability and inhibits synaptic transmission. Ingesting fish meat containing CTX produces an illness very much similar to other food poisoning or gastrointestinal infections. The majority of patients begin to have signs and symptoms of ciguatera within 6 - 10 hours (range 1 - 48) [4]-[7]. Neurological symptoms often manifest early as headache, numbness, "classic" reversal of temperature perception, ataxia (rare) and muscle paralysis. Some sensory symptoms (tingling, cold allodynia or small fiber polyneuropathy) can persist for weeks, but gastrointestinal symptoms (diarrhea, nausea, vomiting) and cardiovascular symptoms (hypotension, cardiac arrhythmias) usually resolve within 2 - 3 days. Fish of the Indian and Pacific oceans contains more CTX toxin than those from the Caribbean [8] and can present with common neurological symptoms [5] [7] consisting of perioral numbness (38\% - 91\%), whole-body or limb paresthesia (36\% - 100\%), temperature dysesthesia (19\% 94\%), dizziness (25\% - 62\%), nausea and vomiting (37\% - 69\%), headache $(19 \%-62 \%)$, limb weakness (30\% $100 \%)$ and myalgia (34\% - 86\%). When compared with puffer fish poisoning, ciguatera has more prominent gastrointestinal symptoms, especially diarrhea (67\% - 83\%) andabdominal pain (30\% - 74\%). There are also reports of cardiac dysrhythmias ( $0 \%-33 \%)$. Generally, the severity of ciguatera is milder than puffer fish poisoning, but it can cause acute and chronic effects that result in hallucination, depression and anxiety [9].

It is difficult to distinguish between puffer fish poisoning and ciguatera toxin. Clinical symptoms of puffer fish poisoning result from tetrodotoxin, a heat-stable and water-soluble molecule that inhibits $\mathrm{Na}^{+}$channel and post-synaptic acetylcholine receptors [10]. This process reduces synaptic transmission. Furthermore, tetrodotoxin can stimulate chemoreceptor trigger zones at the medulla oblongata, causing nausea, vomiting and depression of the respiratory center [11]. Symptoms usually occur within 30 minutes to 6 hours after ingestion of toxin in most of the patients (85\%) [6] [10]-[12]. Normally, the initial symptom of puffer fish poisoning is perioral paresthesia (68\% - 71\%) that can evolve to whole-body or limb paresthesia (34\% - 44\%). Half of the patients have headache $(40 \%-47 \%)$, nausea and vomiting $(45 \%$ - 48\%) and some have dizziness $(22 \%-30 \%)$. The muscle weakness or paralysis begins later $(22 \%-62 \%)$ [11]-[13]. The typical pattern of marine toxin weakness is ascending paralysis with weakness starting at lower extremities then advancing to trunk and upper extremities. Moreover, coma $(0 \%-11 \%)$ and respiratory failure $(0 \%-22 \%)$ can be found in severe cases of tetrodotoxin. For other non-neurological symptoms, patients may have abdominal pain $(17 \%-22 \%)$ but there is no diarrhea. The autonomic nervous system symptoms that have been reported are hypersalivation $(0 \%-11 \%)$ and late cardiac dysfunction (rare) [13].

Marine fish poisoning, although common, has been largely ignored and the frequency is underestimated [14]. This may be attributed to lack of confirmatory tests and seemingly nonspecific clinical presentations. In this study, we reported 6 patients with possible ciguatera poisoning from 2 incidents; two in Bangkok and the remaining 4 patients in Phuket. All had uneventful recoveries.

\section{Case Presentation}

We report six patients from two incidents in 2007 and 2009. The first two were admitted to King Chulalongkorn Memorial Hospital (KCMH) in Bangkok after ingesting contaminated sea bass. The remaining four, were admitted to Phuket Provincial hospital. We included these patients based on the presence of severe diarrhea, nausea and vomiting, absence of reflex tachycardia, and dramatically recovery of clinical symptoms and signs within 24 - 72 hours despite a severe degree of cardiovascular and neuromuscular systems involvement at nadir.

\subsection{First Incident: Patients 1 and 2}

Patient 1 was a 20-year-old pharmacy student. She was previously healthy. On August 31st 2007, she had lunch 
at the dormitory cafeteria, consisting of rice with sea bass. One hour after that, she gradually felt numbness at the perioral area. The numbness progressed to both hands and feet within a few hours. She had dizziness and became clumsy while walking. In the following morning she woke up with severe fatigue, vertigo, nausea and vomiting. Ataxia was noted. She was immediately taken to the hospital. Upon admission, her vital signs were normal with a blood pressure of $110 / 60 \mathrm{mmHg}$, a heart rate of 70 beats per minute. There was no significant focal neurological deficit except for abnormal balance of maintaining posture and ataxia without side predilection. Sensory examination was normal in all modalities. Deep tendon reflexes were normal at $1+$. She received intravenous fluid and antiemetic drug. She was discharged after one day with no sequelae (Table 1).

Patient 2 was a 35-year-old nurse who had been working at King Chulalongkorn Memorial Hospital (KCMH). She had eaten bass with Chinese celery for lunch at the same canteen and the same day as Patient 1 . Half-anhour after her meal, she had abdominal pain and diarrhea. A diminished sensation at perioral area and at both hands was also noted shortly after onset. Within a few hours, her numbness increased in severity. She also felt dizzy, and experienced severe nausea and vomiting. At the emergency department, she was noted having dyspnea which progressed to impending respiratory failure. Two hours later, she developed hoarseness of voice and weakness of all extremities grade 4/5 with preservation of deep tendon reflexes. Her peak respiratory flow was recorded to be less than 300 milliliters and her peripheral oxygen saturation was $57 \%$. Blood pressure was $144 / 100 \mathrm{mmHg}$. Her heart and respiratory rates showed no compensatory responses to severe hypoxia. Heart rate was at 80 beats per minute and respiratory rate was only 20 times per minute. She subsequently developed severe generalized weakness and required end otracheal intubation. Neurology consultation was requested to exclude a diagnosis of brainstem stroke. Upon examination, her muscle tone was flaccid. She had normal pupillary size and responses to light and no abnormal brainstem signs. She was then admitted to the intensive care

\begin{tabular}{|c|c|c|c|c|c|c|}
\hline Patient No. & Patient 1 & Patient 2 & Patient 3 & Patient 4 & Patient 5 & Patient 6 \\
\hline Year & 2007 & 2007 & 2009 & 2009 & 2009 & 2009 \\
\hline Age (year) & 20 & 50 & 9 & 24 & 29 & 34 \\
\hline Hometown & Bangkok & Bangkok & Phuket & Phuket & Phuket & Phuket \\
\hline Gender & Female & Female & Male & Male & Female & Female \\
\hline Onset of symptom & $\begin{array}{l}1 \mathrm{hr} \text { after meal } \\
\text { (16 hrs prior to } \\
\text { admission) }\end{array}$ & $\begin{array}{c}30 \text { min after meal } \\
\text { (6 hrs prior to } \\
\text { admission) }\end{array}$ & $\begin{array}{l}2 \text { hrs after meal } \\
\text { (4 hrs prior to } \\
\text { admission) }\end{array}$ & $\begin{array}{l}2 \text { hrs after meal } \\
\text { (4 hrs prior to } \\
\text { admission) }\end{array}$ & $\begin{array}{l}4 \text { hrs after meal } \\
\text { (4 hrs prior to } \\
\text { admission) }\end{array}$ & $\begin{array}{l}2 \text { hrs after meal } \\
\text { (3 hrs prior to } \\
\text { admission) }\end{array}$ \\
\hline Symptoms & $\begin{array}{l}\text { Perioral/hands/feet } \\
\text { numbness, ataxia, } \\
\text { vertigo, nausea \& } \\
\text { vomitting }\end{array}$ & $\begin{array}{l}\text { Abdominal pain, } \\
\text { diarrhea, perioral } \\
\text { numbness, nausea } \\
\text { \& vomiting }\end{array}$ & $\begin{array}{l}\text { Diarrhea, perioral } \\
\text { \& tongue } \\
\text { numbness, nausea } \\
\text { \& vomiting }\end{array}$ & $\begin{array}{l}\text { Abdominal pain, } \\
\text { perioral } \\
\text { /legs numbness, } \\
\text { nausea, } \\
\text { vomiting, diarrhea }\end{array}$ & $\begin{array}{c}\text { Diarrhea, } \\
\text { Perioral/hands/feet } \\
\text { numbness, nausea, } \\
\text { vomiting, abdominal } \\
\text { pain, cramping }\end{array}$ & $\begin{array}{c}\text { Diarrhea, nausea, } \\
\text { vomiting, } \\
\text { abdominal pain, } \\
\text { cramping, perioral/ } \\
\text { hands/feet } \\
\text { numbness }\end{array}$ \\
\hline $\begin{array}{l}\text { History of food } \\
\text { taking }\end{array}$ & $\begin{array}{l}\text { Sea bass with } \\
\text { Chinese celery }\end{array}$ & $\begin{array}{l}\text { Sea bass with } \\
\text { Chinese celery }\end{array}$ & $\begin{array}{l}\text { Red snapper fish } \\
\text { curry }\end{array}$ & $\begin{array}{l}\text { Red snapper fish } \\
\text { curry }\end{array}$ & $\begin{array}{l}\text { Red snapper fish } \\
\text { curry }\end{array}$ & $\begin{array}{l}\text { Red snapper fish } \\
\text { curry }\end{array}$ \\
\hline Underlying & No & Dyslipidemia & No & No & No & No \\
\hline Vital signs & Normal & Respiratory failure & Hypotension & Normal & Hypotension & Hypotension \\
\hline Conscious & Normal & Normal & Normal & Normal & Normal & Normal \\
\hline Neurosigns & Normal (improved) & $\begin{array}{c}\text { Horseness of voice, } \\
\text { quadriparesis with } \\
\text { normal reflexes }\end{array}$ & Not significant & Not significant & $\begin{array}{c}\text { Not } \\
\text { significant }\end{array}$ & Not significant \\
\hline $\mathrm{CBC}$ & Normal & Normal & NA & NA & NA & Leukocytosis \\
\hline Electrolyte & Normal & Normal & NA & NA & NA & NA \\
\hline Ventilator support & No & Yes & No & No & No & No \\
\hline Result & Recover in 1 day & Recover in 3 days & Recover in 1 day & Recover in 1 day & Recover in 1 day & Recover in 1 day \\
\hline
\end{tabular}


unit (ICU) where she received intravenous fluid and other supportive care including respiratory support. Laboratory investigations revealed normal electrolytes and other blood chemistry. She was on ventilatory support for 24 hours and fully recovered three days after admission (Table 1).

\subsection{Second Incident: Patients 3, 4, 5, and 6}

Patients 3, 4, 5, and 6 were in the same family. On December 12th, 2009 patient 6 prepared red snapper consisting of curry and pork rib soup with salted vegetables. All the twelve members of the family shared the same dinner but only four developed symptoms.

Patient 3 was a 9-year-old boy. Two hours after dinner, he experienced nausea, vomiting and abdominal pain with watery diarrhea (more than 20 stools). He also experienced numbness at his legs, tongue, and perioral region. He was brought to Phuket Provincial Hospital where he was observed to have hypotension and signs of volume depletion with systolic blood pressure lower than $90 \mathrm{mmHg}$ and a heart rate of 80 beats per minute. Neurological examination was within normal limit. The numb feeling around his mouth and legs resolved within 24 hours after he received supportive care and intravenous fluid replacement (Table 1).

The second member of the family was patient 4 . He was a healthy man 24 years of age. Six hours after dinner, when his nephew (patient 3) was hospitalized, he also had nausea and vomiting. He began to feel abdominal cramping, diarrhea and headache. He also noted perioral numbness; of tongue, both hands and feet. Physical examination showed that he was febrile and moderately dehydrated with hypotension (blood pressure of 80/40 $\mathrm{mmHg}$ ) and had a heart rate of 48 per minute. There were no abnormal neurological signs (Table 1). His laboratory investigations were within normal limit. He received supportive care including intravenous fluids, acetaminophen, antiemetic drugs and was well one day after admission.

Patient 5, a 29-year-old housewife, had the longest incubation period of all. She developed symptoms 8 hours after the joint meal. She had nausea, vomiting and watery diarrhea of more than 10 stools along with abdominal pain, perioral numbness and also numbness of hands and feet. Vital signs at admission were normal except for a slow heart rate of 52 beats per minute with a blood pressure of 110/60 mmHg. There was no neurological deficit. Her blood tests were normal. She was admitted for one day observation and received intravenous fluids, antispasmodics and antiemetics (Table 1 ).

Patient 6 was a 34-year-old previously healthy female. She was the one who prepared the food for the whole family. Her symptoms occurred 5 hours after the meal, comprising of perioral and limb numbness, abdominal pain, diarrhea, nausea and vomiting. Physical examination on admission revealed a blood pressure of 90/60 mmHg and a relative sinus bradycardia of 50 beats per minute. She was fully conscious and had no neurological deficits. Her laboratory investigations were within normal limits except leukocytosis of $18,700 \mathrm{cells} / \mathrm{mm}^{3}$. She was admitted for observation for 24 hours and was prescribed only antiemetics and oral rehydration salts. She completely recovered at the time of discharge. Patient 1 had abnormal slow heart rates of 40 - 50 beats/minute whilst in the presence of hypotension/volume depletion and/or hypoxemia. All patients had nausea, vomiting and diarrhea (except patient 1 who had nausea and vomiting).

\section{Discussion}

There are many marine toxins that can cause human diseases after ingesting contaminated food. A history of eating fish points to ciguatera or puffer fish poisoning, whereas consuming shellfish may suggest paralytic, neurotoxic oramnesic shellfish poisoning [6]. Each marine toxin can manifest with different signs and symptoms. Some are unique, but many can be shared. Thus, it is not easy to identify marine toxins clinically. Diagnosis depends on history of eating particular kinds of seafood, symptoms and time to recovery. Detection of toxin in remnants of the food can be done only in special laboratories but is usually not possible due to the unavailability of the food at the time intoxication is suspected.

In 1984, there was one reported case of ciguatoxin poisoning of an Italian visitor who had ingested ocean fish in Thailand [15]. Twenty types of potentially ciguatoxic fish species had been collected from fish markets in Bangkok, Chantaburi and Chonburi. CTX was not detected from any of the meat and livers of these fishes tested by mouse bioassay. Thus we do not know the prevalence of this toxin in fish from this region. In our case series, Patient 1 had perioral numbness 1 hour after eating fish. Within the following 6 hours, she developed whole body paresthesia, severe vertigo, nausea, vomiting and ataxia. It was difficult to diagnose whether she had ciguatera or a mild to moderate form of puffer fish poisoning. But due to prominent vertigo, her illness might be best ex- 
plained by CTX. Patient 2 had onset at 30 minutes. She had abdominal pain and watery diarrhea, perioral and bilateral hand numbness. She felt dizzy, had nausea after 3 hours. At 6 hours, her clinical symptoms worsened and she developed acute respiratory failure. Although muscular paralysis was prominent, diarrhea and abdominal pain are rarely found in puffer fish poisoning (Table 2) [5] [7] [11]-[13]. Patient number 3 also had abdominal pain, watery diarrhea and nausea/vomiting within 2 hours of ingesting fish. Leg numbness had developed later. This case was diagnosed as CTX poisoning because of prominent gastrointestinal symptoms. Patients 4,5 and 6 all had similar symptoms. Their clinical onset ranged from 5 to 8 hours after meal. All three of them had abdominal pain, diarrhea, nausea and vomiting. The interesting point was that all had bradycardia (48, 52 and 50 beats per minute) despite volume depletion and hypotension. Such autonomic involvement in the form of bradycardia [16] or dysrhythmia, abdominal pain, nausea and vomiting and dramatic recovery are indicative of CTX poisoning.

Treatment of CTX poisoning is mainly supportive and symptomatic, such as volume replacement. There are reports suggesting that mannitol, $0.5-1 \mathrm{~g} / \mathrm{kg}$ as an intravenous drip in 30 - 45 minutes within 48 - 72 hours after onset, would help improve the severity of symptoms. Authors believed that due to high osmolarity, mannitol could reduce neuronal edema and act as scavenger of free radicals [17]. However, controlled trials showed that mannitol compared to normal saline infusions could not demonstrate any benefits [18]. Besides, osmotic dieresis, it may actually worsen a patient's condition by increasing volume depletion.

Prevention of ciguatera intoxication is difficult. It is colorless, odorless and has no characteristic taste. Most importantly, CTX is resistant to heat and cannot be destroyed by cooking. The current recommendation is that one should avoid eating internal organs of high risk fishe, such as Moray eel, Barracuda (Pla-saak-yai), Grouper (PlaKao), Kingfish (Pla-sam-lee), Jacks (Pla-ka-mong), Snapper (Pla-kra-pong), Surgeonfish(Pla-kee-tung-bet), Parrot fish (Pla-nok-kaew), Wrasses (Pla-nok-khun-tong), Hogfish, Narrow barred Spanish mackerel (Pla-in-see-bung), Coral trout (Pla-kud-slade), Flowery cod (Pla-ka-rang-siae) and Red emperor (Pla-kra-pong-daeng). If this is not avoidable, it has been suggested to consume ONLY small amounts of the same fish $(<50 \mathrm{~g})$ [5].

\section{Conclusion}

Recent studies have suggested that the increased incidence of ciguatera fish poisoning (CFP) correlates with

Table 2. Clinical symptoms of ciguatera and puffer fish poisoning [4] [6] [10]-[12].

\begin{tabular}{|c|c|c|c|}
\hline Neurological symptoms & Symptoms & Tetrodotoxin & Ciguatoxin \\
\hline & Perioral numbness & $71 \%-68 \%$ & $38 \%-91 \%$ \\
\hline & Generalized paresthesia & $34 \%-44 \%$ & $36 \%-100 \%$ \\
\hline & Temperature dysesthesia & - & $19 \%-94 \%$ \\
\hline & Vertigo & $22 \%-30 \%$ & $25 \%-62 \%$ \\
\hline & Nausea and vomiting & $45 \%-48 \%$ & $37 \%-69 \%$ \\
\hline & Headache & $40 \%-47 \%$ & $19 \%-62 \%$ \\
\hline & Limbs weakness & $22 \%-62 \%$ & $30 \%-100 \%$ \\
\hline & Myalgia & - & $34 \%-86 \%$ \\
\hline & Ataxia & $0 \%-15 \%$ & Rare \\
\hline & Coma & $0 \%-11 \%$ & - \\
\hline & Respiratory failure & $0 \%-22 \%$ & Rare \\
\hline \multicolumn{4}{|l|}{ Gastrointestinal symptoms } \\
\hline & Abdominal pain & $17 \%-22 \%$ & $30 \%-74 \%$ \\
\hline & Diarrhea & $0 \%$ & $67 \%-83 \%$ \\
\hline \multicolumn{4}{|l|}{$\begin{array}{l}\text { Autonomic nervous system } \\
\text { symptoms }\end{array}$} \\
\hline & Hypersalivation & $0 \%-7.5 \%$ & - \\
\hline
\end{tabular}


global warming and other environment disturbances [19]. However, lacking of good serologic and clinical tests for diagnosis of CFP, leaves us with no real scientific basis for this increased reporting. Often, we cannot reliably determine what type of intoxication has actually occurred. Examination of remnants of the food responsible is the method of choice for CFP diagnosis but it is usually impossible because the food had already been discarded. Nevertheless, surveillance of CTX on fish in markets can provide surveillance information and allow warning the public if some species are found with toxins. Although clinical symptoms and signs of ciguatera and tetrodotoxin poisoning can overlap, early prominent gastrointestinal disturbances, relative bradycardia in spite of hypotension, rapid recovery from severe illness and, even ventilatory failure appearing within 1 - 2 days, point to ciguatera poisoning.

\section{Acknowledgements}

This research was sponsored by the Thailand Research Fund (DBG5180026), the Thai Red Cross Society, Thailand, and the US Naval Health Research Center BAA-10-93 under Cooperative Agreement Number W911NF-11-2-004. The views and conclusions contained in this document are those of the authors.

\section{References}

[1] Sobel, J. and Painter, J. (2005) Illnesses Caused by Marine Toxins. Clinical Infectious Diseases, 41, 1290-1296. http://dx.doi.org/10.1086/496926

[2] Goodman, D.M., Rogers, J. and Livingston, E.H. (2013) JAMA Patient Page. Ciguatera Fish Poisoning. Journal of the American Medical Association, 309, 2608. http://dx.doi.org/10.1001/jama.2013.3826

[3] Lovejoy, C., Bowman, J.P. and Hallegraeff, G.M. (1998) Algicidal Effects of a Novel Marine Pseudoalteromonas Isolate (Class Proteobacteria, Gamma Subdivision) on Harmful Algal Bloom Species of the Genera Chattonella, Gymnodinium, and Heterosigma. Applied and Environmental Microbiology, 64, 2806-2813.

[4] Winter, F.D. (2009) Ciguatera Poisoning: An Unwelcome Vacation Experience. Proceedings (Baylor University. Medical Center), 22, 142-143.

[5] Friedman, M.A., Fleming, L.E., Fernandez, M., Bienfang, P., Schrank, K., Dickey, R., Bottein, M.Y., Backer, L., Ayyar, R., Weisman, R., et al. (2008) Ciguatera Fish Poisoning: Treatment, Prevention and Management. Marine Drugs, 6, 456-479. http://dx.doi.org/10.3390/md6030456

[6] Isbister, G.K. and Kiernan, M.C. (2005) Neurotoxic Marine Poisoning. Lancet Neurology, 4, 219-228. http://dx.doi.org/10.1016/S1474-4422(05)70041-7

[7] Wong, C.K., Hung, P., Lee, K.L., Mok, T., Chung, T. and Kam, K.M. (2008) Features of Ciguatera Fish Poisoning Cases in Hong Kong 2004-2007. Biomedical and Environmental Sciences, 21, 521-527. http://dx.doi.org/10.1016/S0895-3988(09)60012-X

[8] Dickey, R.W. and Plakas, S.M. (2001) Ciguatera: A Public Health Perspective. Toxicon, 56, 123-136.

[9] Lewis, R.J. (2001) The Changing Face of Ciguatera. Toxicon, 39, 97-106. http://dx.doi.org/10.1016/S0041-0101(00)00161-6

[10] Noguchi, T. and Arakawa, O. (2008) Tetrodotoxin—Distribution and Accumulation in Aquatic Organisms, and Cases of Human Intoxication. Marine Drugs, 6, 220-242. http://dx.doi.org/10.3390/md20080011

[11] Chowdhury, F.R., Nazmul Ahasan, H.A., Mamunur Rashid, A.K., Al Mamun, A. and Khaliduzzaman, S.M. (2007) Tetrodotoxin Poisoning: A Clinical Analysis, Role of Neostigmine and Short-Term Outcome of 53 Cases. Singapore Medical Journal, 48, 830-833.

[12] Homaira, N., Rahman, M., Luby, S.P., Haider, M.S., Faruque, L.I., Khan, D., Parveen, S. and Gurley, E.S. (2010) Multiple Outbreaks of Puffer Fish Intoxication in Bangladesh, 2008. The American Journal of Tropical Medicine and Hygiene, 83, 440-444. http://dx.doi.org/10.4269/ajtmh.2010.10-0168

[13] Silva, C.C., Zannin, M., Rodrigues, D.S., Santos, C.R., Correa, I.A. and Haddad Junior, V. (2010) Clinical and Epidemiological Study of 27 Poisonings Caused by Ingesting Puffer Fish (Tetrodontidae) in the States of Santa Catarina and Bahia, Brazil. Revista do Instituto de Medicina Tropical de São Paulo, 52, 51-56. http://dx.doi.org/10.1590/S0036-46652010000100009

[14] Skinner, M.P., Brewer, T.D., Johnstone, R., Fleming, L.E. and Lewis, R.J. (2011) Ciguatera Fish Poisoning in the Pacific Islands (1998 to 2008). PLOS Neglected Tropical Diseases, 5, e1416. http://dx.doi.org/10.1371/journal.pntd.0001416

[15] Sozzi, G., Marotta, P., Aldeghi, D., Tredici, G. and Calvi, L. (1988) Polyneuropathy Secondary to Ciguatoxin Poisoning. The Italian Journal of Neurological Sciences, 9, 491-495. http://dx.doi.org/10.1007/BF02337168 
[16] Chan, T.Y. (2013) Severe Bradycardia and Prolonged Hypotension in Ciguatera. Singapore Medical Journal, 54, e120e122. http://dx.doi.org/10.11622/smedj.2013095

[17] Birinyi-Strachan, L.C., Davies, M.J., Lewis, R.J. and Nicholson, G.M. (2005) Neuroprotectant Effects of Iso-Osmolar D-Mannitol to Prevent Pacific Ciguatoxin-1 Induced Alterations in Neuronal Excitability: A Comparison with Other Osmotic Agents and Free Radical Scavengers. Neuropharmacology, 49, 669-686. http://dx.doi.org/10.1016/j.neuropharm.2005.04.024

[18] Schnorf, H., Taurarii, M. and Cundy, T. (2002) Ciguatera Fish Poisoning: A Double-Blind Randomized Trial of Mannitol Therapy. Neurology, 58, 873-880. http://dx.doi.org/10.1212/WNL.58.6.873

[19] Tester, P.A., Feldman, R.L., Nau, A.W., Kibler, S.R. and Wayne Litaker, R. (2010) Ciguatera Fish Poisoning and Sea Surface Temperatures in the Caribbean Sea and the West Indies. Toxicon, 56, 698-710.

http://dx.doi.org/10.1016/j.toxicon.2010.02.026 